\title{
Knowledge Regarding Care of Low Birth Weight Babies among Nurses Working in Pediatric Wards of a University Hospital in Eastern Nepal
}

\author{
- Upendra Yadav ${ }^{1}$ Basant Kumar Karna ${ }^{1}$
}

Submitted 25 January 2021

\section{\# Upendra Yadav upendrayadav@bpkihs.edu \\ iD https://orcid.org/0000-000I-6236-II84 \\ ${ }^{1}$ Department of Child Health Nursing, College of Nursing. B. P. Koirala Insti- tute of Health Sciences, Dharan, Nepal \\ Citation \\ "Yadav U, Karn BK. Knowledge regarding care of low birth weight babies among nurses working in pediatric wards of a university hospital in eastern Nepal. JBPKIHS. 2021;4(1):43-47.}

doi https://doi.org/10.3126/jbpkihs.v4i1.36101

\section{(c) (i) $(9)$}

This work is licensed under a Creative Commons Attribution NonCommercial 4.0 International License.
Accepted 27 April 2021

Published 30 June 2021

Background: Birth weight is the single most important factor determining a newborn's survival chance. Recent development in neonatal care demands nurses to have updated knowledge regarding the care of low birth weight (LBW) babies. We aimed to assess the knowledge regarding care of LBW babies among nurses.

Methods: In this descriptive cross-sectional study, we enrolled 54 nurses working in pediatric wards of BPKIHS. To assess their knowledge regarding the care of LBW babies, a pre-tested self- response questionnaire was administered with focus on six domains: knowledge about care of LBW babies, the kangaroo mother care, adequacy of breast feeding, vaccination, bathing of LBW babies, and prevention of infection. The chi-square test was used to examine the association between different categorical variables and their knowledge.

Results: The majority (83\%) had a Proficiency Certificate in nursing education, $11 \%$ had a Bachelor of Science in nursing education and only $6 \%$ had completed Bachelor in general nursing. More than half $(55.6 \%)$ of the nurses had a job experience of I-5 years. The overall knowledge score (mean \pm SD) among the nurses on care of LBW babies was $86.5 \pm 2.3$. Nurses with Bachelor level of education had better knowledge score (85.5 \pm I5.4) compared to those with proficiency level of education $(75.1 \pm 15.9)(p=$ 0.003).

Conclusion: The knowledge regarding the care of LBW babies among the nurses working in pediatric wards of BPKIHS seemed excellent. Knowledge was better in nurses with higher educational level.

Keywords: Knowledge, Low birth weight, Nurse, Nursing care

\section{Declarations}

Ethics approval and consent to participate: Ethical approval obtained from the Institutional Review Committee, B.P. Koirala Institute of Health Sciences (Ref No. - IRC/ I253/ 0I8).Written informed consent taken from each participant before enrollment.

Consent for publication: Not applicable

Availability of data and materials: The datasets used and/or analyzed during the current study are available from the corresponding author on reasonable request. All relevant data are within the manuscript.

Competing interest: None
Funding: None

Authors' contributions: UY: concept, design, literature search, and manuscript drafting. BKK: concept, design, literature search, manuscript editing and approval.All the authors have read and approved the final manuscript. Acknowledgement: Researchers would like to acknowledge faculties of Child Health Nursing Department, IRC, all the participants and Ward In-charges (Pediatric units), College of Nursing administrative and supportive staffs. 
$\mathrm{L}$ ow birth weight (LBW) is defined as the birth weight of live-born infants below $2500 \mathrm{gm}$, regardless of gestational age [1]. It is the single most important factor determining the survival chances of a newborn [2]. In South Asia, 9.8 million live births in 2015 were LBW, which accounted for nearly half of the total prevalence worldwide [3]. Maternal education, occupation, weight, age $\geq 30$ years, height, previous history of LBW or preterm delivery, presence of anemia or hypertension during pregnancy, time to first antenatal care visit and its frequency, mode of delivery, and gestational age were independent predictors of LBW $[4,5]$.

Maternal knowledge on care of a baby reflects the health and nutritional status of her baby. Nurses from neonatal care centers/ wards play an important role in empowering mothers with knowledge about specialized care to LBW babies. The recent developments in neonatal care technology demand nurses have up-to-date knowledge regarding care of LBW babies. Therefore, this study was conducted to assess the existing knowledge of the nurses working in pediatric wards of B. P. Koirala Institute of Health Sciences (BPKIHS) on the care of LBW babies.

\section{METHODS}

A fter ethical approval from the Institutional Review Committee, this descriptive, cross-sectional study was carried out in the pediatric wards including Nursery, Pediatric Intensive Care Unit and Neonatal Intensive Care Unit of BPKIHS, from March till May 2020. All the nurses working in the study area and agreeing to participate were enrolled. A total enumerative sampling technique was used. The demographic characteristics of nurses, and their educational level were recorded. To assure confidentiality, participants' information were kept anonymous.

A pretested semi-structured self-reporting questionnaire was used to assess the knowledge of nurses regarding care of the LBW babies. The questionnaire had six areas of inquiry: prevention of infection, knowledge about care of LBW babies, bathing of LBW babies, vaccination, adequacy of breast feeding, and the kangaroo mother care (KMC). Each of the six domains had several questions to assess the knowledge in the respective domain. The knowledge of participants was scored based on the techniques described elsewhere [2]. Briefly, each correct response was given a score of one while a wrong or unsure response was scored zero. The maximum score expected for each domain was 100 irrespective of the number of questions. For example, if there were 8 questions in a domain then each question of that domain carried a value of 12.5 [12.5 x 8 (no. of questions) $=100$ weighted]. Weighted values of all questions of each domain were summed up and then categorized into different levels of knowledge. The total knowledge scores in each domain were categorized as poor $(<40$ ), below average ( 41 to 50 ), average ( 51 to $60)$, good (61 to 70) and excellent ( $>70$ ).

The structured questionnaire was pre-tested in one of the wards of BPKIHS on $10 \%$ of the nurses and checked for completeness, clarity, sensitiveness, and consistency. Finally, corrections were done accordingly before commencing the actual data collection. The principal investigator checked the completeness of the data collected.

The data entry was carried out using MS-Excel Program 2007. Frequencies were used to check for outliers and data cleaning was done. The data were analyzed using Statistical Package for the Social Sciences for windows version 11.5 (SPSS Inc; Chicago, IL, USA). For descriptive statistics, frequency, percentage, mean, and standard deviation were used. The chi-square test was used to examine the association between knowledge and different categorical variables. The Independent t-test was used to compare the significance difference between the knowledge score of bachelor level of nursing education and proficiency level nursing education. A p-value < 0.05 was considered as statistically significant.

\section{RESULTS}

total of 54 participants were enrolled. The majority of the nurses (61\%) belonged to the age group of 20-25 years, and $43.6 \%$ were married. The majority (83\%) had a Proficiency Certificate level education in Nursing (PCL Nursing), $11 \%$ had a Bachelor in Science in nursing education (B.Sc. Nursing) and only 6\% were from Bachelor in General Nursing (BN). The majority (96\%) were staff nurses while $4 \%$ were senior staff nurses. More than half (55.6\%) of the nurses had a job experience of 1-5 years. All the nurses felt the need for a refresher training on the LBW babies (Table 1).

All the participants had heard about six domains of care of LBW babies. Most of the participants had good to excellent knowledge in six domains of care of LBW babies (Table 2). The knowledge score (mean \pm SD) among nurses regarding the care of LBW babies 


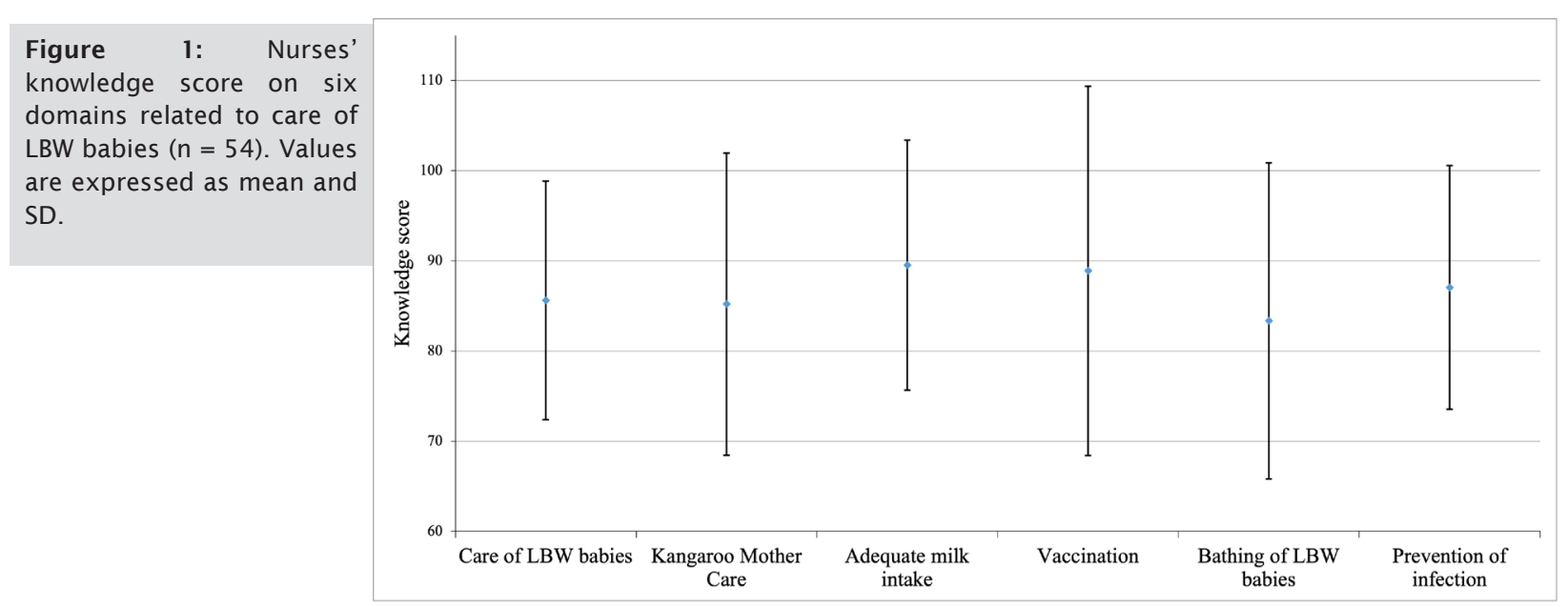

Table 1. Demographic characteristics of study participants $(n=54)$

\begin{tabular}{|c|c|c|}
\hline $\begin{array}{l}\text { Demographic charac- } \\
\text { teristics }\end{array}$ & Categories & $\begin{array}{l}\text { Frequencies } \\
\mathrm{n}(\%)\end{array}$ \\
\hline \multirow[t]{3}{*}{ Age (years) } & $20-25$ & $33(61.0)$ \\
\hline & $26-30$ & $16(30.0)$ \\
\hline & $31-35$ & $5(9.0)$ \\
\hline \multirow[t]{2}{*}{ Marital status } & Married & $23(43.6)$ \\
\hline & Unmarried & $31(57.4)$ \\
\hline \multirow[t]{3}{*}{ Academic level } & PCL Nurse & $45(83.0)$ \\
\hline & $\mathrm{BN}$ & $3(6.0)$ \\
\hline & B. Sc. Nursing & $6(11.0)$ \\
\hline \multirow[t]{2}{*}{ Designation } & Staff Nurse & $52(96.0)$ \\
\hline & Senior Staff Nurse & $2(4.0)$ \\
\hline Total duration of job & < I Years & $6(19.1)$ \\
\hline experience in nursing & I- 5 Years & $30(55.6)$ \\
\hline field & $>5$ Years & 18 (33.3) \\
\hline Duration of service in & < I Years & $18(33.3)$ \\
\hline \multirow[t]{2}{*}{ pediatric units } & I- 5 Years & $24(44.4)$ \\
\hline & $>5$ Years & $12(22.2)$ \\
\hline \multirow[t]{4}{*}{ Area of work } & Pediatric-I & $9(17.0)$ \\
\hline & Pediatric-II & $9(17.0)$ \\
\hline & Neonatal ward & $6(11.0)$ \\
\hline & NICU/ PICU/ Nursery & $30(55.0)$ \\
\hline Work experience at & < I Years & $16(29.6)$ \\
\hline \multirow[t]{2}{*}{ the present ward } & I- 5 Years & $27(50.1)$ \\
\hline & $>5$ Years & II (20.4) \\
\hline $\begin{array}{l}\text { Received training on } \\
\text { any subject related to } \\
\text { care of LBW baby }\end{array}$ & Yes & $18(33.0)$ \\
\hline $\begin{array}{l}\text { Need of refresher } \\
\text { training to nurses on } \\
\text { LBW babies }\end{array}$ & Yes & $54(100)$ \\
\hline
\end{tabular}

was $85.6 \pm 13.2$. The knowledge score (mean $\pm \mathrm{SD}$ ) regarding the $\mathrm{KMC}$ was $85.1 \pm 16.7$, adequate volume of milk intake was $89.5 \pm 13.8$, vaccination of LBW babies $88.8 \pm 20.4$, bathing LBW babies was $83.3 \pm 17.5$, and the prevention of infection was $87.0 \pm 13.5$ (Fig. 1).

No difference was observed in the knowledge about care of LBW babies between junior and senior staff nurses. Nurses having bachelor level of nursing education (B.Sc. Nursing and BN) had better knowledge $(85.5 \pm 15.4)$ compared to the nurses having proficiency level of nursing education $(75.1 \pm 15.9)(\mathrm{p}=0.003)$ while no significant association was found with age, designation, marital status, professional experience in the nursing field, and job experience in the pediatrics unit.

\section{DISCUSSION}

This study found that all the nurses were familiar with the six domains of the care of LBW babies, and the majority had an excellent knowledge regarding the care of LBW babies. We also found that nurses with bachelor level of education had better knowledge compared to nurses with proficiency level education in nursing which is statistically significant irrespective of their designation, marital status, or professional experiences. This finding is consistent with another report [6]. However, a study reported that there is no statistically significant association between duration of work or educational level and respondents' level of knowledge regarding care of LBWs [7].

Our nurses knew the correct definition of LBW while only $45.4 \%$ of nurses in Uganda could tell the correct definition [8]. Similarly, $98.1 \%$ of our nurses knew the definition of intrauterine growth retardation (IUGR). The majority (79.6\%) had heard of Ballard 
Table 2: Knowledge of nurses regarding six domains of care of LBW babies $(n=54)$

\begin{tabular}{|c|c|}
\hline Domain of care & $\begin{array}{l}\text { Correct response } \\
\mathrm{n}(\%)\end{array}$ \\
\hline \multicolumn{2}{|l|}{ Care of LBW babies } \\
\hline Meaning of LBW & $54(100)$ \\
\hline Difference between pre-term and IUGR & $53(98.1)$ \\
\hline $\begin{array}{l}\text { How does LBW babies differ from a normal } \\
\text { newborn babies? }\end{array}$ & $32(59.3)$ \\
\hline $\begin{array}{l}\text { IUGR babies have birth weight }(<10 \text { th per- } \\
\text { centile of expected birth weight) }\end{array}$ & $50(92.6)$ \\
\hline Have you heard about Ballard score? & $43(79.6)$ \\
\hline Feature of prematurity & $29(53.7)$ \\
\hline $\begin{array}{l}\text { Reasons of difficulty in maintaining normal } \\
\text { body temperature in LBW }\end{array}$ & $47(87.0)$ \\
\hline $\begin{array}{l}\text { Meaning of hypothermia of babies (if less than } \\
36.50 \mathrm{C} \text { ) }\end{array}$ & $53(98.1)$ \\
\hline $\begin{array}{l}\text { Best way to keep LBW babies warm (placing } \\
\text { on mother's chest) }\end{array}$ & $54(100)$ \\
\hline \multicolumn{2}{|l|}{ Kangaroo Mother Care } \\
\hline $\begin{array}{l}\text { Temperature of baby to be maintained in } \\
\text { KMC }\end{array}$ & $54(100)$ \\
\hline Does KMC facilitates breast feeding? & $52(96.3)$ \\
\hline Correct techniques of KMC & $42(77.8)$ \\
\hline Best position for mother during KMC & $44(81.5)$ \\
\hline LBW babies should have KMC from birth & $45(83.3)$ \\
\hline Criteria for weaning of babies from KMC & $42(77.8)$ \\
\hline
\end{tabular}

\begin{tabular}{ll}
\hline Adequate volume of milk & $39(72.2)$ \\
\hline $\begin{array}{l}\text { Is a LBW baby to start commercial feeds } \\
\text { immediately? }\end{array}$ & $49(90.7)$ \\
$\begin{array}{l}\text { Condition to stop giving feeding to the baby } \\
\text { Time to provide expressed breast milk to }\end{array}$ & $54(98.1)$ \\
LBW babies & \\
$\begin{array}{l}\text { Correct technique of cup and spoon feeding } \\
\text { to LBW babies }\end{array}$ & $53(98.1)$ \\
$\begin{array}{l}\text { Correct technique of tube feeding to LBW } \\
\text { babies }\end{array}$ & $47(87.0)$ \\
$\begin{array}{l}\text { Initiation of non-nutritive sucking to the } \\
\text { babies }\end{array}$ & $44(81.5)$ \\
\hline \begin{tabular}{l} 
Vaccination \\
\hline Pre-term babies should be vaccinated at the
\end{tabular} & $47(87.0)$ \\
same chronological age as full-term babies \\
$\begin{array}{l}\text { Breast feeding is contraindicated for LBW } \\
\text { babies during vaccination }\end{array}$ & $48(88.9)$ \\
$\begin{array}{l}\text { Dose of vaccine should be reduced for LBW } \\
\text { babies }\end{array}$ & $49(90.7)$ \\
\hline Bathing & \\
\hline LBW babies are given sponging bath only \\
unless the weight of 2.5 kg \\
$\begin{array}{l}\text { Bathing water should feel pleasantly warm to } \\
\text { the elbow or wrist before bathing }\end{array}$ & $50(92.6)$ \\
\hline
\end{tabular}

the elbow or wrist before bathing continued

\begin{tabular}{l}
$\begin{array}{l}\text { Bathing should proceed from soiled to the } \\
\text { cleanest area of the body }\end{array}$ \\
$\begin{array}{l}\text { Bathing and drying should be done quickly } \\
\text { Prevention of infection }\end{array}$ \\
\hline $\begin{array}{l}\text { Not allow the personnel with active infection } \\
\text { be in contact with baby in special care unit }\end{array}$ \\
$\begin{array}{l}\text { Wash hand before and after caring for a baby } \\
\text { and before any procedure }\end{array}$ \\
$\begin{array}{l}\text { Incubators are wiped with disinfectant solu- } \\
\text { tion weekly }\end{array}$ \\
$\begin{array}{l}\text { With each diaper change, the area is washed } \\
\text { using cotton soaked in warm after and dried } \\
\text { carefully }\end{array}$ \\
\hline $\begin{array}{l}\text { LBW: Low birth weight, IUGR: Intrauterine growth retardation, KMC: } \\
\text { Kangaroo mother care }\end{array}$
\end{tabular}

score. Similarly, $87 \%$ of respondents knew that LBW babies have difficulty in maintaining normal body temperature because of less body fat. While all our nurses had a knowledge that the best way to keep LBW babies warm is on the mother's chest, around $2 \%$ did not know the correct definition of hypothermia which is way less than $19 \%$ of respondents from Ethiopia who also could not tell the correct definition of hypothermia [9].

All our nurses knew that the KMC method helps in maintaining body temperature. The majority (96\%) knew that it also facilitates breast feeding. Similarly, $77.8 \%$ responded correctly about techniques of the KMC and $81.5 \%$ responded correctly about the best position for the KMC. The majority (83.3\%) knew that LBW babies should receive the KMC from birth; this finding is also consistent with another study in which $75.6 \%$ of respondents knew about maintaining a skinto-skin contact of a baby with its mother [9]. Among our nurses, $77.8 \%$ knew the correct criteria of weaning from the KMC whereas only $19.7 \%$ of health personnel in another study believed that KMC could be done at home [10].

In our study, around $72 \%$ of nurses were aware that commercial feeds should not be started immediately in LBW babies. Similarly, 91\% knew when to stop feeding a baby. The majority (98.1\%) knew the time to provide expressed breast milk to LBW babies. Our findings are better than a study from Ethiopia where $19 \%$ of midwives felt that mothers should exclusively breastfeed beyond six months [11].

The majority $(87 \%)$ of our nurses knew that preterm infants should be vaccinated at the same 
chronological age as full term. In contrast, a study conducted in India suggested that babies with LBW were vaccinated with a significant delay [12]. Similarly, the majority (88.9\%) of our nurses knew that breast feeding is not contraindicated during vaccination and the majority (90.7\%) knew the correct dosing of vaccines for LBW babies.

Regarding our nurses' knowledge about nutritional supplements of LBWs infants, we found that $87 \%$ knew the correct technique of tube feeding to LBW babies. Interestingly, only less than half of healthcare providers correctly knew the technique of tube feeding to LBW babies in affluent countries as well [13].

More than half $(55.6 \%)$ of our nurses knew that LBW babies should not be bathed unless they weigh 2.5 $\mathrm{kg}$. The majority (92.6\%) of our nurses responded correctly on the way of checking the temperature of the water before bathing. Similarly, the majority (87\%) knew the correct procedure of bathing. Almost $98 \%$ correctly responded that bathing and drying should be done quickly. The findings of our study are consistent with a similar study conducted in the western part of Nepal [7].

All of our nurses knew that they should not allow a person with active infection to be in contact with the baby in the special care unit. Similarly, $98 \%$ of our nurs- es knew about hand washing practices before and after taking care of a baby. A little more than half (51.9\%) of our nurses responded correctly on timing for wiping of incubators. The majority (98\%) knew the correct way of changing diapers.

This study has some limitations. First, the sample size for this study is low and the findings of the study cannot be generalized among all the nurses working at BPKIHS. The main reason for a small sample size was to include the nurses who were working in the pediatric wards only. Second, we did not find any standardized criteria to distinguish knowledge as good and poor. However, we took median value as a cut off value and categorized knowledge as good and poor based on the literature review.

\section{CONCLUSION}

The knowledge regarding the care of LBW babies among the nurses working in pediatric wards of BPKIHS seemed excellent. Knowledge was better in nurses with higher educational level.

\section{References}

I. World Health Organization. International Statistical Classification of Diseases and Related Health Problems. World Health Organization, $2010 ; 10(2)$ : I 52.

2. Kaur R. Staff Nurses (Nicu) knowledge regarding care of low birth weight baby. IOSR Journal of Nursing and Health Science. 20I3: I (3): I-4. DOI: I0.9790/ I959-0130104

3. Blencowe H, Krasevec J, de Onis M, Black RE, An X, Stevens GA et al. National, regional, and worldwide estimates of low birthweight in 2015, with trends from 2000: a systematic analysis. Lancet Glob Health. 2019;7(7):e849-e860. DOI: I0.1016/S22I4109X(18)30565-5

4. Shrestha S, Shrestha S, Shakya Shrestha U, Gyawali K. Predictors of low birth weight at Lumbini Provincial Hospital, Nepal: A hospital-based unmatched case control study. Adv Prev Med. 2020;2020:8459694. DOI: 10.I I55/2020/8459694

5. Bhaskar RK, Deo KK, Neupane U, Chaudhary BS, Yadav BK, Pokharel HP, et al. A case control study on risk factors associated with low birth weight babies in Eastern Nepal. Int J Pediatr. 2015;20 I 5:807373. DOI: I0.I I55/2015/807373

6. Jayanthi V,Arumugam I, Revathi D, Kiran U, Pooja.A study to assess the knowledge regarding low birth weight babies among the nurses working in NICU at Narayana Medical College Hospital, Nellore. Int J Recent Sci Res. 2019; I0(10):35457-60. DOI:10.24327/ ijrsr.2019.1010.4105

7. Kachapati A, Sharma S. Knowledge regarding assessment of high risk neonates among nurses working in selected hospitals of Rupandehi. Journal of Universal College of Medical Sciences. 2018;6(2):5I-5. DOI: 10.3126/jucms.v6i2.22496

8. Ayiasi RM, Criel B, Orach CG, Nabiwemba E, Kolsteren P. Primary healthcare worker knowledge related to prenatal and immediate newborn care: a cross sectional study in Masindi, Uganda. BMC Health Serv Res. 20 |4; |4:65. DOI: I0. I |86/|472-6963- |4-65

9. Berhe AK, Tinsae F, Gebreegziabher G. Knowledge and practice of immediate newborn care among health care providers in eastern zone public health facilities, Tigray, Ethiopia, 2016. BMC Pediatr. 2017; I7(I): I57. DOI: I0.1 I86/s I 2887-017-0915-8

10. Dalal A, Bala DV, Chauhan S.A cross-sectional study on knowledge and attitude regarding kangaroo mother care practice among health care providers in Ahmedabad District. Int J Med Sci Public Health. 20 I4;3(3):253-6. DOI: I 0.5455/ijmsph.20I3.09I220I3 I

II. Arba A, Zana Z. Knowledge of essential newborn care and associated factors among nurses and midwives: a cross-sectional study at public health facilities in Wolaita Zone, Southern Ethiopia, 2019. Int J Pediatr. 2020;2020:3647309. DOI: I0. I I55/2020/3647309

12. Soans S, Mihalyi A, Berlaimont V, Kolhapure S, Dash R, Agrawal A. Vaccination in preterm and low birth weight infants in India [published online ahead of print, 202 I Feb 18]. Hum Vaccin Immunother. 202 I; I-I2. DOI: I0.1080/2 I6455 I 5.2020.1866950.

13. El-Morsy HAS, El-Sayed R, El-Sayed H, El Aziz MAA. The effect of implementing a guideline protocol on nurses' knowledge about the nutritional requirements of low birth-weight infants. American Journal of Nursing Research. 2020;8(I):9-17. DOI:I0.1269I/ ajnr-8-I-2 